\title{
The effect of HER2 expression on cisplatin-based chemotherapy in advanced non-small cell lung cancer patients Zuleyha Calikusu*1, Yesim Yildirim² ${ }^{2}$ Zafer Akcali ${ }^{3}$, Hakan Sakalli³, Nebil Bal ${ }^{4}$, Ilker Unal ${ }^{5}$ and Ozgur Ozyilkan ${ }^{3}$
}

\author{
Address: ${ }^{1}$ Department of Medical Oncology, Acibadem Maslak Hospital, İstanbul, Turkey, ${ }^{2}$ Department of Medical Oncology, Sivas Numune \\ Hospital, Sivas, Turkey, ${ }^{3}$ Department of Medical Oncology, Baskent University Faculty of Medicine, Ankara, Turkey, ${ }^{4}$ Department of Pathology, \\ Baskent University Faculty of Medicine, Ankara, Turkey and ${ }^{5}$ Department of Biostatistics, Cukurova University Faculty of Medicine, Adana, Turkey \\ Email: Zuleyha Calikusu* - zuleyha2004@hotmail.com; Yesim Yildirim - dryesimyildirim@ hotmail.com; \\ Zafer Akcali - zaferakcali@yahoo.com; Hakan Sakalli - hakansakalli1@yahoo.com; Nebil Bal - nebilbal@yahoo.com; \\ Ilker Unal - ilkerun@cu.edu.tr; Ozgur Ozyilkan - ozyilkano@hotmail.com \\ * Corresponding author
}

Published: 3 July 2009

Journal of Experimental \& Clinical Cancer Research 2009, 28:97 doi:10.1 I86/1756-9966-28-97

This article is available from: http://www.jeccr.com/content/28/1/97

(C) 2009 Calikusu et al; licensee BioMed Central Ltd.

This is an Open Access article distributed under the terms of the Creative Commons Attribution License (http://creativecommons.org/licenses/by/2.0), which permits unrestricted use, distribution, and reproduction in any medium, provided the original work is properly cited.
Received: 26 February 2009

Accepted: 3 July 2009

\begin{abstract}
Introduction: The prognostic value of HER2 expression in patients with advanced non-small cell lung cancer remains controversial. The relationship between HER2 expression, and platinum resistance and patient survival, was investigated.

Methods: Seventy-three consecutive patients (median age, 6I years) with stage IIIB and IV nonsmall cell lung cancer, admitted between February 2004 and December 2006, were included in this study. Sixty-one patients received gemcitabine, given as two $1250 \mathrm{mg} / \mathrm{m}^{2}$ doses on days I and 8 and, cisplatin, given as a $75 \mathrm{mg} / \mathrm{m}^{2}$ dose on day 8 . Twelve patients received vinorelbine, given as two 25 $\mathrm{mg} / \mathrm{m}^{2}$ doses on day $\mathrm{I}$ and 8 , and cisplatin, given as a $75 \mathrm{mg} / \mathrm{m}^{2}$ dose on day $\mathrm{I}$. Both treatment paradigms were repeated on a 21 -day cycle. Tumor response was evaluated by comparing tumor size on computerized tomography scans before and after three cycles of chemotherapy. HER2 status was examined by immunohistochemical analysis of paraffin-embedded specimens.
\end{abstract}

Results: HER2 was positive in 2 I of 73 patients (28.8\%). Of the 2 I patients with HER2 positivity, I3 (6I.9\%) responded to chemotherapy with either a complete response, partial remission, or evidence of stable disease. Of 52 HER2-negative patients, 48 (92.3\%) exhibited a response to chemotherapy. The difference in response to therapy between HER2-positive and -negative patients was statistically significant $(p=0.003)$. The median overall survival duration for all patients was 13 months. Median overall survival time was 14 months for HER2-negative patients and 10 months for HER2-positive patients (log-rank $p=0.007$ ).

Conclusion: Non-small cell lung cancer patients with high expression of HER2 exhibited resistance to cisplatin-based chemotherapies that are the standard treatment for this disease. Our results indicate that HER2 status may be a predictive and prognostic factor for cisplatin- based therapy response and disease survival. 


\section{Introduction}

Non-small-cell lung cancer (NSCLC) is a leading cause of cancer deaths worldwide [1]. The prognosis of patients with advanced NSCLC remains poor despite increased understanding of the disease and therapeutic advances, heightening the need for new therapeutic approaches. Modern therapeutic strategies have achieved 1-year survival rates of up to $50 \%$ [2]. A combination of cisplatin or carboplatin with third generation agents, such as gemcitabine, paclitaxel, docetaxel, or vinorelbine, represents the standard of care for fit patients with advanced disease [35]. However, appreciable clinical response to chemotherapy is achieved in only $30-40 \%$ of patients, probably because of relatively higher chemoresistance intrinsic to NSCLC. The mechanism of this resistance is not well understood. Resistance does not appear to correlate with MDR1 gene expression [6], but several reports have linked NSCLC chemoresistance to mutations in TP53 and/or overexpression of HER2. The therapeutic efficacy of anticancer agents is strongly dependent on the ability of the drugs to trigger apoptosis in target tumor cells [7].

Because further advances in chemotherapy are likely to be limited, the key to improving outcomes for NSCLC patients may turn on targeted therapeutic strategies. In particular, agents that target the epidermal growth factor receptor (EGFR) may have a major impact on the treatment of advanced NSCLC $[8,9]$.

The HER2/neu oncogene, a probable prognostic indicator in lung cancer patients, is a member of the EGFR family. Also known as c-erbB-2, HER2 is encoded by a gene located in the chromosomal region 17q11.2-q12, and encodes a transmembrane receptor-type tyrosine-protein kinase [10]. Dimerization of HER2/neu with an activated EGFR molecule activates a signal transduction cascade that leads to an increase in cell proliferation, angiogenesis, and metastatic potential, and a decrease in apoptosis. HER2/neu overexpression is found more often in breast, ovarian, and lung cancer, especially adenocarcinoma [10], and can be detected by immunohistochemistry (IHC). Clinical trials indicate that angiogenesis is more active in tumor tissues in which HER2 is activated, and have suggested that this may lead to platinum resistance $[11,12]$. Tsai and colleagues, using a panel of 20 NSCLC lines obtained from untreated patients, found that overexpression of HER2 was a marker for intrinsic multidrug resistance [6]. HER2-mediated chemoresistance depended on the type of drug used, cell type, and HER2 expression level [10]. The aim of the current study was to investigate the relationship between HER2 expression in non-small cell lung cancer patients, and to assess the effect of this expression on cisplatin-based chemoresistance.

\section{Patients and methods \\ Patients}

Seventy-three consecutive, previously untreated advanced non-small cell lung cancer patients referred to Baskent University Medical Faculty Medical Oncology Department between February 2004 and December 2006 were included in the study. All patients were diagnosed with stage IIIB with pleural effusion or stage IV, according to the American Joint Committee on Cancer staging system (AJCC) 1997. The performance status of patients was 0-2 according to the Eastern Cooperative Oncology Group (ECOG) scale. The studied patients included four females and 69 males with a median age of 61 years (range, 35-78 years). Bone marrow, renal and hepatic functions were sufficient for patients to take part in the study. Twodimensional lesions, measurable by radiologic imaging and physical examination, were taken into account for follow-up criteria. Patients with no measurable masses and concomitant life-threatening diseases were not included in the study.

\section{Treatment}

Sixty-one patients received gemcitabine, given as two $1250-\mathrm{mg} / \mathrm{m}^{2}$ doses on days 1 and 8 and, cisplatin, given as a $75-\mathrm{mg} / \mathrm{m}^{2}$ dose on day 8 [13]. Twelve patients received vinorelbine given as two $25-\mathrm{mg} / \mathrm{m}^{2}$ doses on day 1 and 8 and, cisplatin, given as a $75-\mathrm{mg} / \mathrm{m}^{2}$ dose on day 1 . Both gemcitabine/cisplatin and vinorelbine/cisplatin treatment paradigms were repeated on a 21-day cycle. Patients received a total of four to six chemotherapy courses. Twenty patients received palliative radiotherapy; eight received radiotherapy for bone metastases and twelve received radiotherapy for cranial metastases before the first chemotherapy course.

\section{Treatment evaluation}

Prior to treatment, all patients were evaluated by physical examination, electrocardiography, chest X-ray, bone scintigraphy, thorax computerized tomography (CT), and upper abdominal ultrasound and CT; complete blood counts were also performed. Cranial computerized tomography or magnetic resonance imaging was performed in patients with signs or symptoms of central nervous system disease.

Tumor response was evaluated after the third chemotherapy course by comparison of tumor size on CT scans before and after chemotherapy. We used World Health Organization (WHO) guidelines for response criteria throughout the study. Objective response was defined as follows: complete response (CR) - complete resolution of all disease lasting at least 1 month; partial response (PR) - a decrease $\geq 50 \%$ lasting at least 1 month; stable disease 
(SD) - a decrease of $<50 \%$ or an increase of $<25 \%$ in lesions; and progressive disease (PD) - 25\% or more increase in the size of one or more lesions, or the appearance of new lesions.

\section{IHC}

Tumor-containing tissue slices for examination by IHC were selected from archived paraffin-embedded pathology laboratory specimens. Five-micron thick slices were deparaffinized, and then processed for antigenic retrieval by suspending in a $10-\mathrm{mM}$ citrate buffer solution ( $\mathrm{pH} 6.0$ ) and boiling in a microwave oven for 5 minutes at $500 \mathrm{~W}$, 5 minutes at $400 \mathrm{~W}$ and 5 minutes at $350 \mathrm{~W}$. Specimens were kept in a $3 \%$ hydrogen peroxide solution to remove endogenous peroxides, and then incubated for 5 minutes with Ultra V block (TP-125-HU, Thermo Fisher Scientific Inc., USA) to reduce background. A solution of HER2 antibody (Clone e2-4001 + 3B5, Ready to Use for Immunohistochemical Staining, NeoMarkers/Labvision, USA) was added drop-wise to the slices and incubated for $45 \mathrm{~min}$ utes at room temperature. After washing for 10 with Trisbuffered saline (TBS), biotin-conjugated TP-125-HB (goat anti-polyvalent) was applie and allowed to stand for 10 minutes. Slide- mounted slices were again washed with TBS (10 minutes) and then incubated with streptavidin peroxide for 15 minutes. Slices were then washed for 10 minutes with TBS, and 3-amino-9-ethylcarbazole (AEC) chromogenic substrate (RTU lot: 065020) was added dropwise. Slices were stored in the dark after counterstaining with Mayer's Hematoxylin. Under a light microscope, brown-red coloration in tumor cytoplasmic membranes was considered HER2 positive. Unstained membranes were considered negative (-); pale and partial membranous staining in less than $10 \%$ of tumor cells was given a score of $1+$; pale and complete staining in more than $10 \%$ of tumor cells was given a score of 2+; and strong and complete staining in more than $10 \%$ of tumor cells was given a score of $3+$.

\section{Statistical analysis}

SPSS (Statistical Package for Social Sciences) version 16 was used to analyze the results. After descriptive statistical analyses, survival curves were drawn according to the Kaplan Meier method. The differences between survival curves were analyzed using log-rank tests. Chi-square tests were used to investigate differences between proportions. The effects of histopathology, HER2-positivity and stage of disease on survival were investigated using a Cox Regression Model. Values of $\mathrm{p}<0.05$ were considered statistically significant.

\section{Results \\ Patient characteristics}

Seventy-three patients with non-small cell lung cancer were evaluated between February 2004 and December
2006. Thirty patients (41\%) had stage IIIB disease, and 43 (59\%) stage IV. Histopathological types were squamous cell carcinoma in 34 patients (46.5\%), adenocarcinoma in 27 (37\%) and histopathologically non-small cell lung cancer not otherwise specified (NOS) in 12 (16.5\%).

The median follow-up time was 13 months (range, 2-44 months). At the end of follow-up, 66 patients (90.4\%) had died and $7(9.6 \%)$ survived. During the follow-up period, metastases were detected in bone (13 patients), brain (10 patients), adrenal gland ( 2 patients), pericardium (1 patient), and leptomeninges (1 patient).

\section{HER2 expression and response to chemotherapy}

Tumors were HER2-positive in 21 of 73 patients $(28.8 \%)$; of these, 5 patient specimens were scored as $1+, 102+$ and $63+$. IHC staining for HER2 in relation to clinical characteristics of patients and histological tumor type is shown in Table 1. There was no correlation between the expression of HER2 and the age of patients, stage of tumor, or histological tumor type. One patient showed a complete response (CR) to chemotherapy, and 32 patients exhibited partial response (PR). Disease stabilization (SD) was confirmed in 28 patients, and progressive disease (PD) was manifest in 12. For purposes of statistical analysis, $\mathrm{CR}, \mathrm{PR}$, and SD were evaluated together as a single group and PD was evaluated separately as a second group. Of the HER2-positive patients, $61.9 \%(13 / 21)$ showed a response to chemotherapy $(\mathrm{CR}+\mathrm{PR}+\mathrm{SD})$; among HER2negative patients, $92.3 \%$ (48/52) responded to chemotherapy. The response to therapy was significantly lower in HER2-positive patients than in HER2-negative patients ( $p=0.003$, chi-squared test; Table 2 ). There was no correlation between the response to chemotherapy and clinical characteristics of patients, stage of tumor, or histological type (Table 3).

Table I: Immunohistochemical staining for HER 2 according to clinical characteristics of patients, stage and histological type of tumor

\begin{tabular}{lcc}
\hline Patient characteristics & Number of patients & HER 2 +(\%) \\
\hline Total Patients & 73 & $21(28.8)$ \\
\hline Sex & & \\
Male & 69 & $19(27.5)$ \\
Female & 4 & $2(50)$ \\
\hline Stage & & \\
Stage IIIB & 30 & $9(30)$ \\
Stage IV & 43 & $12(27.9)$ \\
\hline Histopathology & & \\
Adenocarcinoma & & $11(40.7)$ \\
Squamous cell (Epidermoid) & 34 & $5(14.7)$ \\
Not otherwise specified (NOS) & 12 & $5(41.6)$ \\
\hline
\end{tabular}


Table 2: Response to chemoterapy according to expression of HER 2

\begin{tabular}{lll}
\hline HER 2 & CR+PR+SD & PD \\
\hline HER 2 (+) & $13(63.9)$ & $8(38.1 \%)$ \\
\hline HER 2 (-) & $48(92.3 \%)$ & $4(7.7 \%)$
\end{tabular}

\section{Survival}

Median overall survival for all 73 patients was 13 months. For Her2-negative patients, median overall survival was 14 months, whereas for HER2-positive patients, median overall survival was 10 months, a difference that was statistically significant ( $p=0.007$, log-rank test). Survival curves are shown in Figure 1. One-year survival probabilities were $76.9 \%$ for HER2-negative patients and $42.9 \%$ for HER2-positive patients; the corresponding 2-year survival rates were $51.9 \%$ and $0 \%$, respectively.

\section{Cox's regression analyses}

After correcting for age, gender, and stage, HER2 positivity was found to increase the individual death risk by $2.104-$ fold (95\% CI: 1.206-3.670; p = 0.009).

\section{Discussion}

In this study, we detected HER2 overexpression in 22 of 73 tumors $(28.8 \%)$ using immunohistochemistry. The mean percentage of non-small cell lung carcinomas reported to overexpress HER2 ranges from $18-55 \%$, with an average of $31 \%$ [14]. This diversity of results probably reflects differences in methodologies, which have included flow cytometry, IHC, and Western blotting. Moreover, the cut-off point for HER2 positivity varied among studies, ranging from $5 \%$ to $10 \%[15,16]$. In our study, we used $10 \%$ as the cut-off point. Patients with a
HER2 positivity score of +1 to +3 by IHC staining criteria were defined as HER2-positive. The frequency of HER2 staining differed among non-small cell lung cancer subtypes, and was much higher for adenocarcinoma than for squamous or large-cell carcinomas [14-17]. We observed similar results in our study.

Trastuzumab, a monoclonal antibody that binds to HER2, was originally developed for use against breast cancer. Recently, a number of phase II trials have been conducted to evaluate the response of NSCLC to trastuzumab [18]. Some of these trials enrolled lung cancer patients with +2 or +3 HER2 expression scores; however, others included patients with tumor HER2-positive scores of +1 to +3 [18]. Because of these differences in enrollment criteria, it is not clear to what degree HER2 overexpression is a prerequisite for trastuzumab effectiveness.

There have been conflicting reports on the prognostic value of HER2 overexpression. Recently, Nakamura and colleagues published a meta-analysis to assess the association of HER2 overexpression with prognosis in NSCLC [19]. A total of 2,579 patients were included in the final analysis, which concluded that survival at 3 and 5 years was significantly poorer in patients with HER2 overexpression [19].

Different hypotheses have been proposed to explain the poor prognosis of patients with HER2-overexpressing tumor cells. One suggestion is the intrinsic resistance to cytotoxic agents is high in HER2-expressing tumor cells. It is known that high levels of HER2 expression in breast cancer predict resistance to adjuvant chemotherapy [20], and HER2 overexpression has been associated with poor prognosis in breast cancer [21]. The intrinsic chemoresistance of HER2-overexpressing NSCLC lines was investi-

Table 3: Response to chemoterapy according to clinical characteristics of patients and histological type of tumor

\begin{tabular}{|c|c|c|c|}
\hline Patient characteristics & Number of patients & $C R+P R+S D$ & PD \\
\hline Total Patients & 73 & $61(83.6 \%)$ & $12(16.4 \%)$ \\
\hline \multicolumn{4}{|l|}{ Sex } \\
\hline Male & 69 & $58(84 \%)$ & II (I6\%) \\
\hline Female & 4 & $3(75 \%)$ & I (25\%) \\
\hline \multicolumn{4}{|l|}{ Stage } \\
\hline Stage IIIB & 30 & $29(96.6 \%)$ & I(3.4\%) \\
\hline Stage IV & 43 & $32(74.4 \%)$ & II (25.6\%) \\
\hline \multicolumn{4}{|l|}{ Histopathology } \\
\hline Adenocarcinoma & 27 & $2 \mathrm{I}(78 \%)$ & $6(22 \%)$ \\
\hline Squamous cell (Epidermoid) & 34 & $31(91.2 \%)$ & $3(8.8 \%)$ \\
\hline Not otherwise specified (NOS) & 12 & $9(75 \%)$ & $3(25 \%)$ \\
\hline
\end{tabular}




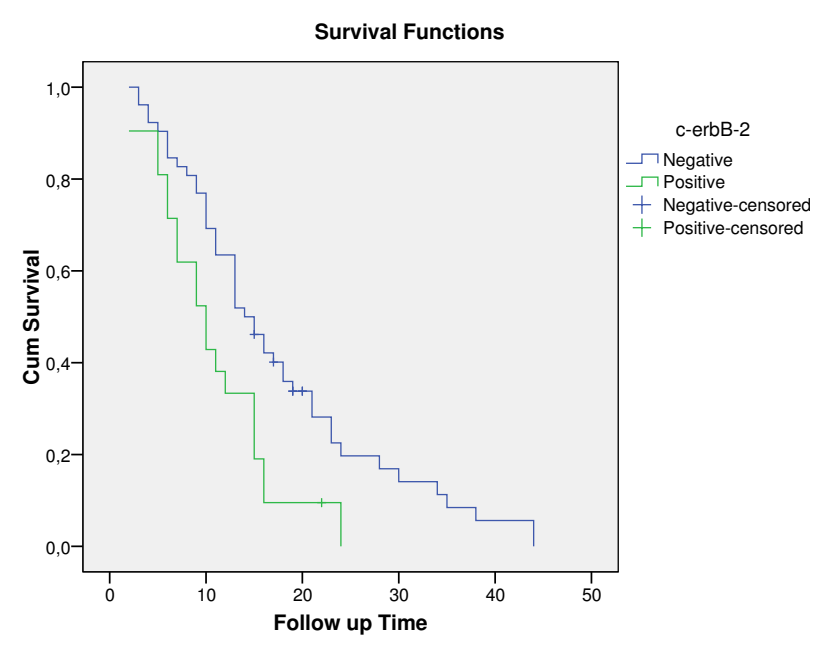

Figure I

Overall survival for the c-erbB-2 (-) and c-erbB-2 (+) patients (months), Kaplan-Meier curve.

gated by Tsai and associates, who showed that resistance to the cytotoxicity of doxorubicin and cisplatin increased with greater expression of HER2 [6].

Recently, investigations into the relationship between p53 and HER2 expression, and response to neoadjuvant chemotherapy, in resected lung cancer demonstrated a tendency toward chemoresistance in tumors with a high level of HER2 expression [16]. Although cisplatin-based combination chemotherapies are the standard treatment for NSCLC [3], our study clearly showed a lower response to cisplatin-based chemotherapy in HER2-positive patients than in HER2-negative patients. The median overall survival was also reduced in HER2-positive patients. These results suggest that NSCLC patients with HER2-overexpressing tumors may require a more potent chemotherapy regimen to achieve longer survival. HER2 status thus seems to be both a predictive and a prognostic factor for cisplatin- based therapy response and disease survival.

Immunohistochemistry is a commonly used method to detect HER2 in different tumor types. Fluorescence in situ hybridization (FISH), another method often used to evaluate HER2 status, mainly determines HER2 gene copy number [22]. Recently, comparisons of IHC and FISH techniques in breast cancer have shown that FISH is more specific than IHC [22]. In NSCLC, the optimal technique for showing HER2 overexpression has not yet been determined. Unlike the situation in breast cancer, HER2 overexpression in NSCLC is more likely caused by chromosomal duplication rather than gene amplification
[23]. Recently, Kuyama and co-workers investigated the relationship between HER2 expression and treatment outcome in locally advanced lung carcinoma using both methodologies [24]. The HER2-FISH results were marginally correlated with IHC results, and only the HER2-FISH data were determined to be an independent factor for poor prognosis of cisplatin-based chemotherapy and survival [24]. In our study, we measured HER2 protein expression by IHC. Although FISH results are demonstrably better for determining HER2 status in breast cancer, until it becomes clear which method is better for evaluating HER2 status in NSCLC, IHC remains a widely available, simple, and less expensive method for determining HER2 expression.

\section{Conclusion}

Despite advances in chemotherapy, the prognosis for NSCLC patients remains poor. Many factors, including HER2 overexpression, may contribute to this adverse outcome Only a few studies have correlated HER2 status and cisplatin-based chemotherapy resistance. Here, we showed that advanced NSCLC that express a high level of HER2 are resistant to cisplatin-based chemotherapies, which are the standard for this disease. HER2 status thus appears to represent both a predictive and prognostic factor for advanced NSCLC.

\section{Competing interests}

The authors declare that they have no competing interests.

\section{Authors' contributions}

ZC participated in coordination of the study. YY participated in the design of the study and drafted the manuscript. ZA participated in the sequence alignment. HS paricipated in the sequence alignment. NB participated in the pathological examination. IU performed the statistical analysis. OO participated in its design and coordination.

\section{Acknowledgements}

We thank Timur KOCA (MD) from Erzurum Numune Hospital, Department of Radiation Oncology, for his valuable contribution to this study.

\section{References}

I. Greenlee RT, Hill-Harmon MB, Murray T, Thun M: Cancer statistics. CA Cancer J Clin 200I, 5 I:I5-36.

2. Sandler A, Gray R, Perry MC, Brahmer J, Schiller JH, Dowlati A, Lilenbaum R, Johnson DH: Paclitaxel-carboplatin alone or with bevacizumab for non-small-cell lung cancer. NEJM 2006, 14;355(24):2542-50.

3. Schiller JH, Harrington D, Belani CP, Langer C, Sandler A, Krook J, Zhu J, Johnson DH, Eastern Cooperative Oncology Group: Comparison of four chemotherapy regimens for advanced nonsmall-cell lung cancer. N Engl J Med 2002, 346:92-98.

4. Kelly K, Crowley J, Bunn PA Jr, Presant CA, Grevstad PK, Moinpour CM, Ramsey SD, Wozniak AJ, Weiss GR, Moore DF, et al.: Randomized phase III trial of paclitaxel plus carboplatin versus vinorelbine plus cisplatin in the treatment of patients with advanced non-small-cell lung cancer: a Southwest Oncology Group trial. J Clin Oncol 2001, 19:3210-3218. 
5. Fossella F, Pereira JR, Pawel JV, Pluzanska A, Gorbounova V, Kaukel E, Mattson KV, Ramlau R, Szczesna A, Fidias P: Randomized, multinational, phase III study of docetaxel plus platinum combinations versus vinorelbine plus cisplatin for advanced nonsmall-cell lung cancer: the TAX 326 study group. J Clin Oncol. 2004, 2 I (I6):3016-3024.

6. Tsai CM, Chang KT, Perng RP, Mitsudomi T, Chen MH, Kadoyama C, Gazdar AF: Correlation of intrinsic chemoresistance of nonsmall cell lung cancer cell lines with HER-2/neu gene expression but not with ras gene mutation. J NCl 1993, 85:897-90I.

7. Hickman JA: Apoptozis and chemotherapy resistance. Eur J Cancer 1996, 32A:921-6.

8. Shepherd FA, Rodrigues Pereira J, Ciuleanu T, Tan EH, Hirsh V, Thongprasert S, Campos D, Maoleekoonpiroj S, Smylie M, Martins R, et al.: National Cancer Institute of Canada Clinical Trials Group Erlotinib in previously treated non-small-cell lung cancer. N Engl J Med 2005, 353:123-132.

9. Sandler AB, Gray R, Brahmer J, Dowlati A, Schiller JH, Perry MC Johnson DH: Randomized Phase II/III Trial of paclitaxel (P) plus carboplatin (C) with or without bevacizumab (NSC \#704865) in patients with advanced non-squamous nonsmall cell lung cancer (NSCLC): an Eastern Cooperative Oncology Group (ECOG) Trial - E4599. Proc Am Soc Clin Oncol 2005, 23:A4

10. Hung M-C, Lau Y-K: Basic science of HER-2/neu: a review. Semin Oncol 1999, 26:5I-9.

II. Jammato T, Ikava S, Akiyama T, Semba K: Similary of protein encoded by the human c-erbB2 gene to epidermal growth factor receptor. Nature 1986, 319:230-4.

12. Olagione MA, Meve RM, Lane HA, Hynes NE: The erb-B signaling network: receptor heterodimerization in development and cancer. $E M B O$ J 2000, 19:3159-67.

13. Akcali Z, Calikusu Z, Sakalli H, Ozyilkan O: Gemcitabine and cisplatin treatment of advanced-stage non-small-cell lung cancer in patients given cisplatin on day 8. Tumori 2008, 94(4):474-80.

14. Hirsch FR, Franklin WA, Veve R, Varella-Garcia M, Bunn PA: Her2I neu expression in malignant lung tumors. Semin Oncol. 2002, 29(I Suppl 4):5I-58.

15. Onn A, Correa AM, Gilcrease M, Isobe T, Massarelli E, Bucana CD, O'Reilly MS, Hong WK, Fidler IJ, Putnam JB, et al.: Synchronous overexpression of epidermal growth factor receptor and HER2/neu protein is a predictor of poor outcome in patients with stage I non-small cell lung cancer patients. Clin Cancer Res 2004, 10:136-143.

16. Fijolek J, Wiatr E, Rowinska-Zakrewska E, Giedronowicz D, Langfort R, Chabowski M, Orlowski T, Roszkowski K: P53 and Her2/neu expression in relation to chemotherapy response in patients with non-small cell lung cancer. Int J Biol Markers 2006, 2 I:8I-87.

17. Junker K, Stachetzki U, Rademacher D, Linder A, Macha HN, Heinecke A, Müller KM, Thomas M: Her2/neu expression and amplification in non-small cell lung cancer prior to and after neoadjuvant therapy. Lung Cancer 1998, 22:181-190.

18. Azoli GH, Krug LM, Miller VA, Kris MG, Mass R: Trastuzumab in the treatment of non-small cell lung cancer. Seminars in Oncol 2002, 29(suppl 4):59-65.

19. Nakamura H, Kawasaki N, Taguchi M, Kabasawa K: Association of Her-2 overexpression with prognosis in nonsmall cell lung carcinoma: A metaanalysis. Cancer 2005, 103:|865-1873.

20. Allred DC, Clark GM, Tandon AK, Tormey CD, Osborne CK, MCGuire WL: Her-2/neu in node negative breast cancer: prognostic significance of overexpression Influenced by presence of in situ carcinoma. J Clin Oncol 1992, 10:599-605.

21. Slamon DJ, Leyland-Jones B, Sahk S, Fuchs H, Paton V, Bajamonde A, Fleming T, Eiermann W, Wolter J, Pegram M, et al:: Use of chemotherapy plus monoclonal antibody against HER2 for metastatic breast cancer. N Engl J Med 200I, 344:783-792.

22. Pauletti G, Dandekar S, Rong H, Ramos L, Peng H, Seshadri R, Slamon $D$ J: Assessment of methods for tissue-based detection of the Her-2/neu alteration in human breast cancer: a direct comparison of fluorescence in situ hybridization and immunohistochemistry. J Clin Oncol 2000, 18:365I-3664.

23. Hirsch F, Veve R, Varella-Garcia M, Bunn PA, Franklin WA: Evaluation of HER2/neu expression in lung tumors by immunohistochemistry and fluorescence in situ hybridization (FISH). Proc Am Soc Clin Oncol 2000, 19:486a. (abstr 1900)
24. Kuyama S, Hotta K, Tabata M, Segawa $Y$, Fujiwara $Y$, Takigawa N, Kiura K, Ueoka H, Eguchi K, Tanimoto M: Impact of Her2 gene and protein status on the treatment outcome of cisplatinbased chemotherapy for locally advanced nonsmall cell lung cancer. J Thorac Oncol. 2008, 3(5):477-48I.
Publish with Bio Med Central and every scientist can read your work free of charge

"BioMed Central will be the most significant development for disseminating the results of biomedical research in our lifetime. "

Sir Paul Nurse, Cancer Research UK

Your research papers will be:

- available free of charge to the entire biomedical community

- peer reviewed and published immediately upon acceptance

- cited in PubMed and archived on PubMed Central

- yours - you keep the copyright

Submit your manuscript here:

http://www.biomedcentral.com/info/publishing_adv.asp
BioMedcentral 